\title{
Advanced Metal Oxides and Nitrides Thermoelectric Materials for Energy Harvesting
}

\author{
Yining Feng, ${ }^{1}$ Evan Witkoske, ${ }^{2}$ Elizabeth S Bell, ${ }^{3}$ Yang Wang, ${ }^{4}$ Athanasios Tzempelikos, ${ }^{5}$ Ian T. Ferguson, ${ }^{6}$ and Na Lu ${ }^{1,2,4}$
}

Metal oxides and nitrides are widely used in many applications as a result of their high mechanical, chemical, and electrical properties. In high temperature thermoelectric applications, oxides and nitrides exhibit high thermopower and thermal stability. Moreover, most oxides and nitrides are consisted of earth abundant elements, which are non-toxic, cost effective and easy for large-scale synthesis. In this article, we reviewed the recent advances of metal oxides and nitrides and their applications in thermoelectrics. The materials that are examined include both p-type semiconductors (e.g. $\mathrm{Na}_{\mathrm{x}} \mathrm{CoO}_{2}, \mathrm{Ca}_{3} \mathrm{Co}_{4} \mathrm{O}_{9}, \mathrm{GaN}$ ) and n-type semiconductors (e.g. ZnO-based, $\mathrm{SrTiO}$, InGaN, InN). This study is focused on the temperature dependent thermoelectric transport properties of oxides and nitrides aiming for reaching a high power factor.

Keywords: Oxides; Nitrides; Thermoelectric; Figure of Merit; Power Generation

Received 24 August 2018, Accepted 8 October 2018

DOI: $10.30919 / \mathrm{esmm} 5 \mathrm{f} 116$

\section{Introduction}

It is evident that thermoelectric (TE) devices are the important advancement in the renewable energy field. They are able to directly convert heat into electricity via the Seebeck effect, which could take advantages of the waste heat generated by various processes. ${ }^{1-3}$ Factories, homes and even the human body can be used as heat sources for TE devices. However, the biggest challenge standing in the way of TE devices is the suitable materials with high power factor, an indicator of a large voltage with high current will be generated using TE devices. So far TE devices have mainly been limited to niche applications such as power generation space and

${ }^{1}$ Lyles School of Civil Engineering, Birck Nanotechnology Center, Sustainable Materials and Renewable Technology (SMART) Lab, Purdue University, West Lafayette, IN 47906 USA

${ }^{2}$ School of Electrical and Computer Engineering, Birck Nanotechnology Center, Sustainable Materials and Renewable Technology (SMART) Lab, Purdue University, West Lafayette, IN 47906 USA

${ }^{3}$ Davidson School of Chemical Engineering, Sustainable Materials and Renewable Technology (SMART) Lab, Purdue University, West Lafayette, IN 47906 USA

${ }^{4}$ School of Materials Engineering, Birck Nanotechnology Center, Sustainable Materials and Renewable Technology (SMART) Lab, Purdue University, West Lafayette, IN 47906 USA

${ }^{5}$ Lyles School of Civil Engineering, Center for High Performance Buildings, Ray W. Herrick Laboratories, Purdue University, West Lafayette, IN 47906, USA

${ }^{6}$ Electrical and Computer Engineering, Missouri University of Science and Technology, Rolla MO 65409, USA

*E-mail: luna@purdue.edu medical devices, where the benefits of a stable energy source are worth the high cost and low efficiency of typical TE materials. ${ }^{4-6}$ There are hopes of using TE devices for broader applications including electricity production in rural areas, enhancement of solar panels, energy recovery from the exhaust pipes of cars, and wearable flexible devices. ${ }^{7-9}$ However, the use of TE devices will not become widespread until more efficient, environmentally friendly, and cost effective TE materials are produced.

There are several factors to determine the quality of materials for TE applications, which have been combined into one parameter called the figure of merit, $z T . z T=\frac{s^{2} \sigma T}{\kappa}$ where $S$ is the Seebeck coefficient, $\sigma$ is electrical conductivity, $\mathrm{T}$ is absolute temperature, and $\kappa$ is thermal conductivity, which includes both electron and lattice thermal conductivity. ${ }^{5,10}$ A high Seebeck coefficient, high electrical conductivity, and low thermal conductivity are ideal for TE materials. This combination is challenging because electrical and themal conductivity often go hand in hand, as stated in the Wiedemann-Franz law, so improving one parameter often simutantlously improves another property. ${ }^{1,10}$ Ideal TE materials should scatter the movement of phonons, the major heat-carrying component of a material, while allowing charge carriers, electrons and holes, to flow freely. ${ }^{11}$

For TE power generation, it is important to look at power factor (PF), which is defined as $S^{2} \sigma .^{12} \mathrm{PF}$ indicates the voltage output under a certain temperature difference.

It is urgent to search for high PF TE materials as most of current TE materials have achieved the high $z T$ value owing to their low thermal conductivity, which does not ensure that it will be able to produce a large amount of power. Therefore increasing the power factor should be a major goal in the development of new TE materials for power generation, but making sure the figure of merit remains fairly high is still necessary. ${ }^{13}$

To this end, we focused on reviewing the recent advancement in 


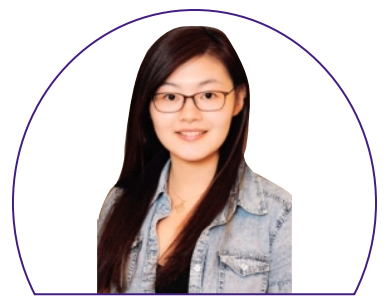

Yining Feng

Yining Feng is pursuing her PhD degree of Civil Engineering at Purdue University. She is also a guest graduate student at Argonne National Lab. Her current research interests range from nanostructured oxides for high temperature thermoelectric applications to flexible thermoelectric devices for medium to low temperature applications. Yining has published one book chapter, ten journal papers and three conference proceeding. Yining has attended the 2017 National Science Foundation (NSF) Innovation Corps (ICorps) as an entrepreneur lead on high temperature thermoelectric technology development.

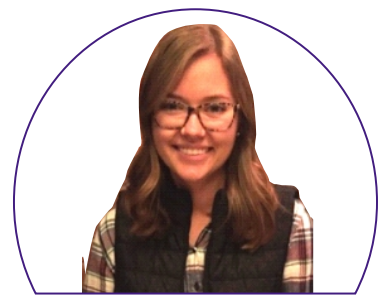

Elizabeth Bell

Elizabeth Bell is pursuing her bachelor of chemical engineering from the Davidson School of Chemical Engineering at Purdue University. Her research is concentrated on the properties of potential materials for thermoelectric devices.

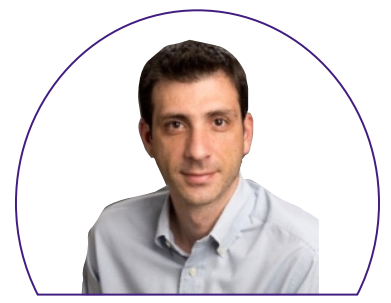

Athanasios (Thanos) Tzempelikos

Dr. Athanasios (Thanos) Tzempelikos is an associate professor of Civil Engineering with courtesy appointment in Mechanical Engineering at Purdue University, and a faculty member of the Center for High Performance Buildings. His research focuses on smart building design and operation, multifunctional dynamic building facades, indoor environmental comfort, daylighting, preference-based personalized controls, and solar energy utilization in buildings.

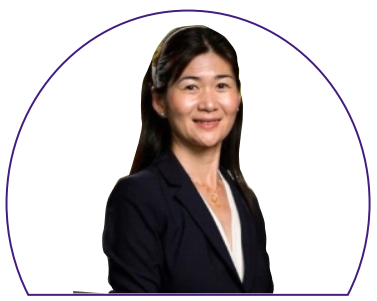

Na (Luna) Lu

$\mathrm{Na}$ (Luna) Lu is an associate professor of the Lyles School of Civil Engineering, School of Materials Engineering and faculty-in-residence at Birck Nanotechnology Center at Purdue University. Her research focuses on functional nanomaterials synthesis and device development for energy harvesting and sensing applications, particularly, thermoelectric, piezoelectric and solar cells. Lu has authored over 80 technic publications; 1 book, 4 book chapters, 1 patent and 3 provisional patents. Dr. Lu has received several prestigious scientific awards including NSF CAREER award for thermoelectric materials study.

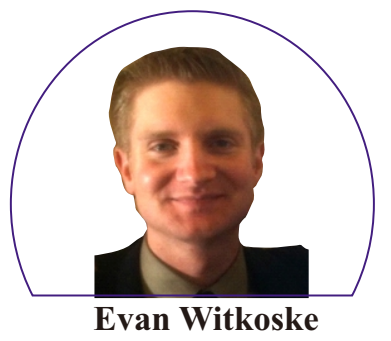

Evan Witkoske received a bachelor's degree with majors in Physics, Mathematics, and Statistics, while minoring in Electrical and Computer Engineering and Economics and a Masters in ECE at Purdue University. He is currently pursuing a PhD degree in Electrical Engineering under the instruction of Professors Mark S. Lundstrom and Na (Luna) Lu at Purdue University. His current research interests include theoretical characterization and simulation of nanoscale thermoelectric transport.

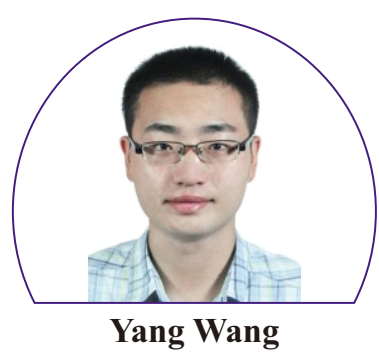

Yang Wang is a PhD student at school of Material Science Engineering. His research focuses on nanomaterials for energy harvesting and MOCVD growth of $\mathrm{ZnO}$ based materials.

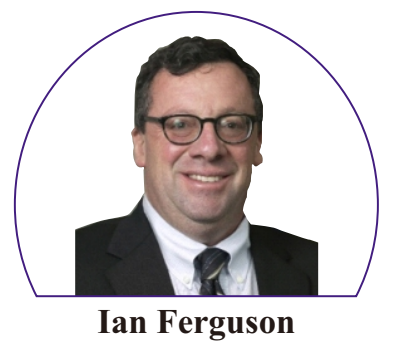

Dr. Ian Ferguson is a member of faculty in the Electrical and Computer Engineering Department at Missouri University of Science and Technology. His research has focused on the area of wide bandgap materials and devices and developing these materials for applications in the areas of illumination, solar power, spintronics, and nuclear detection. Dr. Ferguson is a Fellow of the Royal Society of Arts, Manufactures and Commerce (FRSA) in addition to being a Fellow IEEE. IOP and SPIE. 
n- and p-type oxide and nitride materials, particularly $\mathrm{ZnO}$-based alloy, ${ }^{14} \mathrm{Na}_{\mathrm{x}} \mathrm{CoO}_{2},{ }^{15} \mathrm{Ca}_{3} \mathrm{Co}_{4} \mathrm{O}_{9},{ }^{16} \mathrm{SrTiO}_{3},{ }^{17} \mathrm{InN},{ }^{18} \mathrm{InGaN}_{,}{ }^{19} \mathrm{AlGaN}^{20}$ and $\mathrm{GaN}^{21}$ since these materials typically have large PF. The temperature dependent TE transport properties of these materials are summarized and analyzed.

\section{TE Properties of Oxides Materials}

There is a promising opportunity for metal oxides used as TE materials because of their non-toxicity, cost effective, and high thermal stability compared to conventional TE materials. ${ }^{11,22}$ Also, by altering their crystal structures and chemical compositions, electronic properties can be manipulated from insulator to metallic conductor behavior, which leads to a higher power factor. ${ }^{23}$ Waste heat sources are often free and unlimited, so materials with high power factor are more important than figure of merit for many TE power generation applications. ${ }^{5}$ The following sections review the TE properties of the most common n- and p-type of metal oxides materials.

\subsection{N-type Oxides}

\subsubsection{ZnO-based}

The direct band gap of Zinc oxide $(\mathrm{ZnO})$ is reported as $3.37 \mathrm{eV}$, which also shows large exciton binding energy of $60 \mathrm{meV}^{24}$ It is a promising candidate for n-type TE material used in high temperature energy harvesting. ${ }^{25-27}$ The study showed the PF of bulk $\mathrm{ZnO}$ to be about $0.75 \times 10^{-4} \mathrm{~W} / \mathrm{mK}^{2}$ at carrier concentration $\left(\mathrm{n} \sim 10^{-17} \mathrm{~cm}^{-3}\right)$ at room temperature. The high $\mathrm{PF}$ can be attributed to the high crystal quality, which resulted in a favorable Seebeck coefficient ( $\sim 78$ $\mu \mathrm{V} / \mathrm{K}){ }^{28}$

Although pure $\mathrm{ZnO}$ already has high Seebeck coefficient, significant enhancement of TE power factor and Seebeck coefficient is reported with $\mathrm{Ga}^{29}$ and In-Al ${ }^{30}$ doping. As shown in Fig. 1, the maximum power factor value of $12.5 \times 10^{-4} \mathrm{~W} / \mathrm{mK}^{2}$ at $1273 \mathrm{~K}$ observed in $\mathrm{Zn}_{0.985} \mathrm{Ga}_{0.015} \mathrm{O}$ yields $\mathrm{zT}_{\max }$ of 0.25 . Sean et $a l^{30}$ reported that $(\mathrm{ZnO}) \mathrm{Al}_{0.03} \mathrm{In}_{0.02}$ exhibited the best TE properties with a $\mathrm{PF}$ of $22.1 \times 10^{-4} \mathrm{~W} / \mathrm{mK}^{2}$ at $975 \mathrm{~K}$. From this study, an electrical conductivity of $5.88 \times 10^{2} \mathrm{~S} / \mathrm{cm}$ and Seebeck coefficient of -220 $\mu \mathrm{V} / \mathrm{K}$ has been reported. The PF is three times greater than that of the film without In dopants.

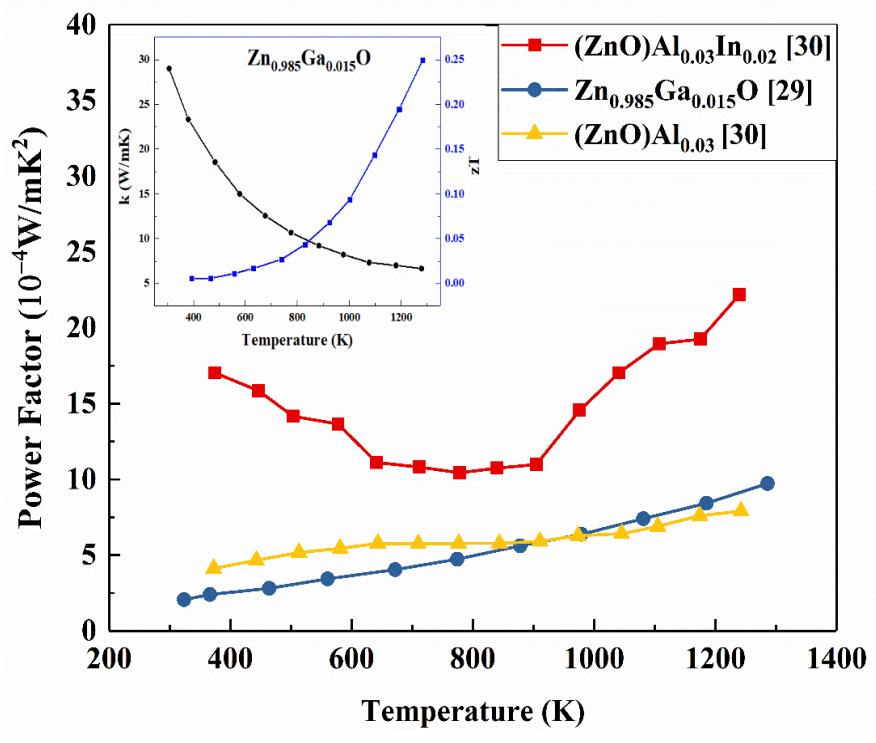

Fig. 1 Temperature dependence of TE properties of $\mathrm{ZnO}$.
P-type doping of $\mathrm{ZnO}$ has been found to be very difficult. Ideally, group-I ( $\mathrm{Li}$ and $\mathrm{Na})$, group $\mathrm{V}(\mathrm{N}, \mathrm{P}, \mathrm{As}, \mathrm{Sb}$ and $\mathrm{Bi})$, and group IB ( $\mathrm{Cu}$ and $\mathrm{Ag}$ ) elements could be p-type dopants. However, it is still very challenging due to the stability and reliability of p-type $\mathrm{ZnO}^{31}$

\subsection{2 $\mathrm{SrTiO}_{3}$}

Strontium titanate $\left(\mathrm{SrTiO}_{3}\right)$-based perovskite oxide materials have shown potential applications as n-type TE materials at low temperature. ${ }^{32}$ Nag et al. reported that at high doping concentration $\left(\mathrm{n} \sim 10^{21} \mathrm{~cm}^{-3}\right)$ and its high electron mobility $\left(10 \mathrm{~cm}^{2} \mathrm{~V}^{-1} \mathrm{~s}^{-1}\right.$ to $100 \mathrm{~cm}^{2} \mathrm{~V}$ $\left.{ }^{1} \mathrm{~s}^{-1}\right)$ lead to good electrical conductivity. ${ }^{33}$ Also, the study showed the large effective mass $\left(\mathrm{m}^{*} \sim 2-16 \mathrm{~m}_{0}\right)^{34,35}$ caused by the material's d-band nature and conduction band degeneracy. ${ }^{36,37}$ Additionally, introducing oxygen vacancies or substitutional doping of $\mathrm{Sr}^{2+}$ or $\mathrm{Ti}^{4+}$ sites with higher valence elements will change the electrical conductivity of $\mathrm{SrTiO}_{3}$ from insulating to metallic behavior. ${ }^{35,38,39}$

Fig. 2 shows that $\mathrm{Sr}_{0.95} \mathrm{La}_{0.05} \mathrm{TiO}_{3}$ reaches a maximum $\mathrm{PF}$ of $28 \times 10^{-4} \mathrm{~W} / \mathrm{mK}^{2}$ at $320 \mathrm{~K}$ and carrier density of $0.2-2 \times 10^{21} \mathrm{~cm}^{-3},{ }^{37}$ a value comparable to the $\mathrm{PF}$ of the most commonly used low temperature TE material, $\mathrm{Bi}_{2} \mathrm{Te}_{3}$. This performance arises from the high Seebeck coefficient $(\sim 350 \mu \mathrm{V} / \mathrm{K})$, which is due to high degeneracy of the conduction band and the high energy-dependent scattering rate. The rare earth elements Sm, Dy and Y have smaller ionic radii ${ }^{+}$, which reduce lattice parameter. ${ }^{40}$ The La and Dy codoped $\mathrm{La}_{0.08} \mathrm{Dy}_{0.12} \mathrm{Sr}_{0.8} \mathrm{TiO}_{3}$ has a lower PF owing to the decreased electrical conductivity. The decrease in conductivity which comes from the reduced carrier mobility due to the formation of the second phase $\left(\mathrm{Dy}_{2} \mathrm{Ti}_{2} \mathrm{O}_{7}\right)$ during the doping mechanism. ${ }^{41}$

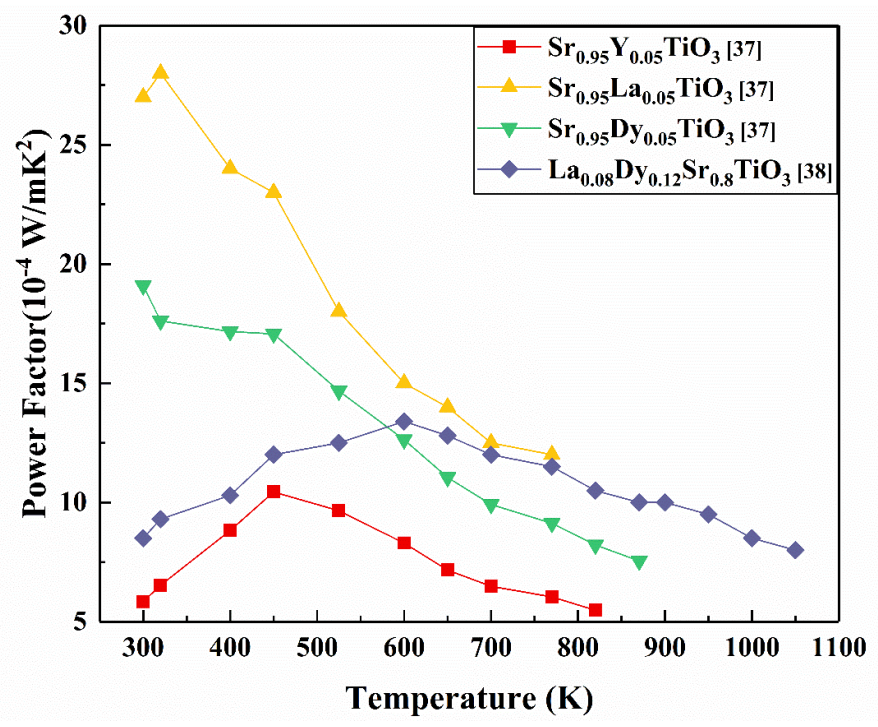

Fig. 2 Temperature dependence of TE properties of $\mathrm{Sr}_{\mathrm{x}} \mathrm{TiO}_{3}$.

\subsection{P-type Oxides}

\section{$2.21 \mathrm{Na}_{x} \mathrm{CoO}_{2}$}

$\mathrm{Na}_{\mathrm{x}} \mathrm{CoO}_{2}$ has a hexagonal layered crystal structure formed by alternating sodium ion $\left(\mathrm{Na}^{+}\right)$and $\mathrm{CoO}_{2}$ planes along the $c$ axis. The structure of this material gives phonons and electrons different transport paths. ${ }^{42}$ Electrons and holes pass through the $\mathrm{CoO}_{2}$ layer during p-type conduction, whereas the disordered $\mathrm{Na}^{+}$layer provides the channel for phonon movement. Thus, this type of layered structure will simultaneously provide high electrical conductivity 
and low thermal conductivity, which is referred to as "phonon glass electron crystal" behavior, ${ }^{33}$ an ideal combination for TE applications. Therefore, it has been recognized that p-type alkali cobalt oxides as highly promising oxide TE materials. ${ }^{43}$ The study reported polycrystalline $\mathrm{Na}_{0.8} \mathrm{CoO}_{2}$ exhibited a high $\mathrm{PF}$ of $14 \times 10^{-4}$ $\mathrm{W} / \mathrm{mK}^{2}$ at $300 \mathrm{~K}^{15,44}$

The effects of different dopants and doping levels have been widely investigated for $\mathrm{Na}_{\mathrm{x}} \mathrm{CoO}_{2}$. Fig. 3 shows a summary of the effects of various dopants on PF. Ag doping can increase both the electrical conductivity and Seebeck coefficient of $\mathrm{Na}_{\mathrm{x}} \mathrm{CoO}_{2}$, resulting in a high $\mathrm{PF}$ value. It was expected the increase in electrical conductivity since Ag is a metal-phase dopant. However, it is not clear that the mechanism of the enhancement of the Seebeck coefficient. One possibility could be caused by the uniformity of $\mathrm{Ag}$ doping throughout the sample. ${ }^{45}$ With $10 \% \mathrm{Ag}$ doping, $\mathrm{Na}_{\mathrm{x}} \mathrm{CoO}_{2}$ reached a $\mathrm{PF}$ of $18.92 \times 10^{-4} \mathrm{~W} / \mathrm{mK}^{2}$ at $\sim 1100 \mathrm{~K}$ with a doping concentration of $\sim 10^{21} \mathrm{~cm}^{-3}$. 46

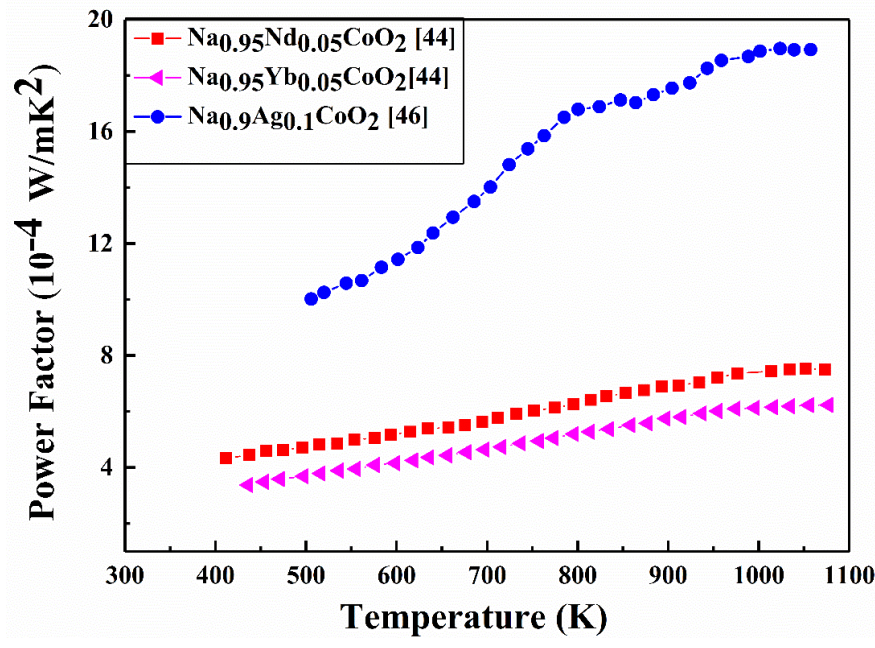

Fig. 3 Temperature dependence of TE properties of $\mathrm{Na}_{x} \mathrm{CoO}_{2}$.

\subsection{2 $\mathrm{Ca}_{3} \mathrm{Co}_{4} \mathrm{O}_{9}$}

$\mathrm{Ca}_{3} \mathrm{Co}_{4} \mathrm{O}_{9}$ is also a promising p-type oxide because of good electrical properties. ${ }^{47,48} \mathrm{Ca}_{3} \mathrm{Co}_{4} \mathrm{O}_{9}$ has stacked crystal structure that $\mathrm{CoO}_{2}$ and $\mathrm{Ca}_{2} \mathrm{CoO}_{3}$ layers alternating along the $c$ axis. The $\mathrm{CoO}_{2}$ planes are mainly responsible for electrical conduction, and the $\mathrm{Ca}_{2} \mathrm{CoO}_{3}$ interlayers transfer heat by phonons. Un-doped polycrystalline $\mathrm{Ca}_{3} \mathrm{Co}_{4} \mathrm{O}_{9}$ shows a room temperature Seebeck coefficient of 150 $\mu \mathrm{V} / \mathrm{K}$, electrical conductivity of $80 \mathrm{~S} / \mathrm{cm}$, and PF of $1.5 \times 10^{-4}$ $\mathrm{W} / \mathrm{mK}^{2}{ }_{49}$ However, using nobles metals such as Ag as a dopant at the $\mathrm{Ca}$ cationic atom site can both increase thermopower and electrical transport properties, which lead to increased PF values. ${ }^{50}$ This can be attributed to more improvement for the Fermi level $\left(\mathrm{E}_{\mathrm{F}}\right)$ than the valence band energy $\left(\mathrm{E}_{\mathrm{v}}\right)$ of the crystal materials, which resulting from substituting $\mathrm{Ag}^{+}$for $\mathrm{Ca}^{2+}$ in $\mathrm{Ca}_{3-\mathrm{x}} \mathrm{Ag}_{\mathrm{x}} \mathrm{Co}_{4} \mathrm{O}_{9}(0<\mathrm{x}<$ $0.3) .{ }^{51}$ For TE materials, the Seebeck coefficient is proportional to the difference between the Fermi level and valence band energy $\left(\mathrm{E}_{\mathrm{F}}\right.$ $\mathrm{E}_{\mathrm{V}}$ ), which indicates that $\mathrm{Ag}$ doping in $\mathrm{Ca}_{3} \mathrm{Co}_{4} \mathrm{O}_{9}$ can increase the Seebeck coefficient. The $\mathrm{PF}$ of $\mathrm{Ca}_{3} \mathrm{Co}_{4} \mathrm{O}_{9}$ is much smaller than that of $\mathrm{Na}_{\mathrm{x}} \mathrm{CoO}_{2}$ at $300 \mathrm{~K}$, but $\mathrm{Ca}_{3} \mathrm{Co}_{4} \mathrm{O}_{9}$ is being more commonly used in TE applications. It is more stable with different compositional changes. ${ }^{52}$ Fig. 4 shows the effects of doping $\mathrm{Ca}_{3} \mathrm{Co}_{4} \mathrm{O}_{9}$ with different transition metal elements. The PF increases with temperature for all of the dopants. ${ }^{53,54}$ Substituting transition elements (i.e. Fe, Bi, Mn, Ba, Ga) for $\mathrm{Ca}$ or $\mathrm{Co}$ is also effective in increasing the $\mathrm{PF}$ of $\mathrm{Ca}_{3} \mathrm{Co}_{4} \mathrm{O}_{9}$. The
Fe-doped $\mathrm{Ca}_{3} \mathrm{Co}_{4} \mathrm{O}_{9}$ has a significant increase in PF from $2.3 \times 10^{-4}$ $\mathrm{W} / \mathrm{mK}^{2}$ to $6.10 \times 10^{-4} \mathrm{~W} / \mathrm{mK}^{2}$ at $\sim 1000 \mathrm{~K}$ as shown in figure. This is due to the substitution of $\mathrm{Fe}$ ions for $\mathrm{Co}$ ions in the $\mathrm{CoO}_{2}$ layers changes the electronic structure and increases the electronic correlations. Thus, Fe is an effective dopant, which increases both Seebeck coefficient and electrical conductivity. ${ }^{54}$

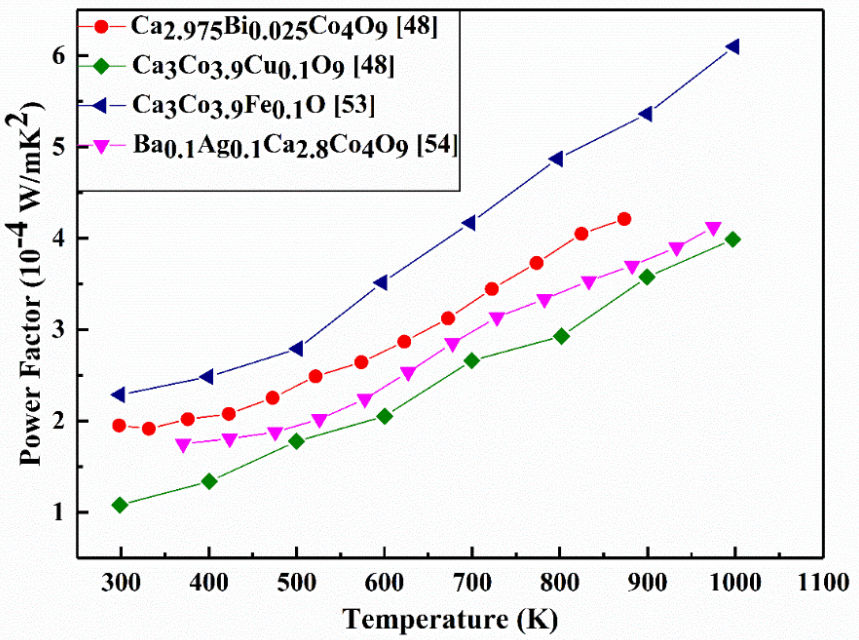

Fig. 4 Temperature dependence of TE properties of $\mathrm{Ca}_{3} \mathrm{Co}_{4} \mathrm{O}_{9}$.

\section{TE Properties of Nitrides Materials}

III-nitrides are used in a wide variety of applications, such as lightemitting diodes (LEDs), optical and electronic devices, and ultraviolet (UV) detectors. ${ }^{22}$ These materials are considered for TE applications for a variety of reasons, including low material cost, high thermal stability, high mechanical strength, and radiation hardness. ${ }^{55,56}$ III-nitrides also generally can be alloyed or nanostructured during the fabrication process, which allows the ability to tune TE properties. ${ }^{56-58}$ Due to the wide bandgap property in many $\mathrm{N}$ based materials, III-Nitrides can maintain a high Seebeck coefficient at high temperatures without the excitation of minority carriers and the loss of the n- or p- type character of the materials. ${ }^{22,59}$ With this array of unique properties and fabrication possibilities, III-nitrides offer a promising solution for developing viable TE devices that would operate at high temperatures, where most current TE materials are limited to less than $800 \mathrm{~K} .{ }^{60}$ The synthesis methods and quality of nitride-based materials are continually improving due to their usefulness in a variety of applications. ${ }^{22}$ The following sections review the TE properties of the most common n- and p-types of IIInitride materials and their notable alloys.

\subsection{N-type Nitrides}

\subsubsection{InN}

Indium nitride ( $\mathrm{InN}$ ) can be considered a third-generation semiconductor material which has only recently gained increased interests. InN has a band gap of $0.7 \mathrm{eV}^{61}$, which displays good electrical conductivity even at intrinsic carrier concentrations. Similar to $\mathrm{GaN}$, InN has a wurtzite crystal structure with lattice constants $3.574 \AA$ and $5.704 \AA$ for a and c, which are higher than GaN due to indium's larger atomic mass. ${ }^{62}$

A reasonable estimate of the maximum Seebeck at $900 \mathrm{~K}$ can be obtained using InN's band gap of $0.7 \mathrm{eV}$, yielding a value of around $390 \mu \mathrm{V} / \mathrm{K} .63$ Fig. 5 shows electrical conductivity versus temperature for three Fermi level values of $0.108 \mathrm{eV}, 0.025 \mathrm{eV}$ and $0.011 \mathrm{eV}$ 
corresponding to carrier concentrations of $6 \times 10^{18} \mathrm{~cm}^{-3}, 9 \times 10^{17} \mathrm{~cm}^{-3}$ and $4 \times 10^{17} \mathrm{~cm}^{-3}$, respectively. Due to the low effective mass of 0.05 $\mathrm{m}_{0}$ of this narrow band gap material, ${ }^{64}$ we expect this material to have a large electrical conductivity. The lattice conductivity has not been extensively studied, however due to its larger discrepancy between constituent elements, one would expect its thermal conductivity below that of $\mathrm{GaN}$. We do observe a reduction in lattice thermal conductivity from $\mathrm{InN}$ at room temperature, however the reduction is only on the order of 3-4 times that of $\mathrm{GaN}^{65}$ In Fig. 6, the $z T$ is shown for bulk $\mathrm{InN}$ as well as for $\mathrm{InN}$ nanowires with varying diameters. The largest $z T$ value of 1.6 is obtained for the $6 \mathrm{~nm}$ nanowire at $1000 \mathrm{~K}$, which is much larger than the value at room temperature for this same structure. This shows indium nitride's potential for high temperature TE applications through the use of nanostructuring, which reduces dimensionality to increase the overall figure of merit. ${ }^{66}$

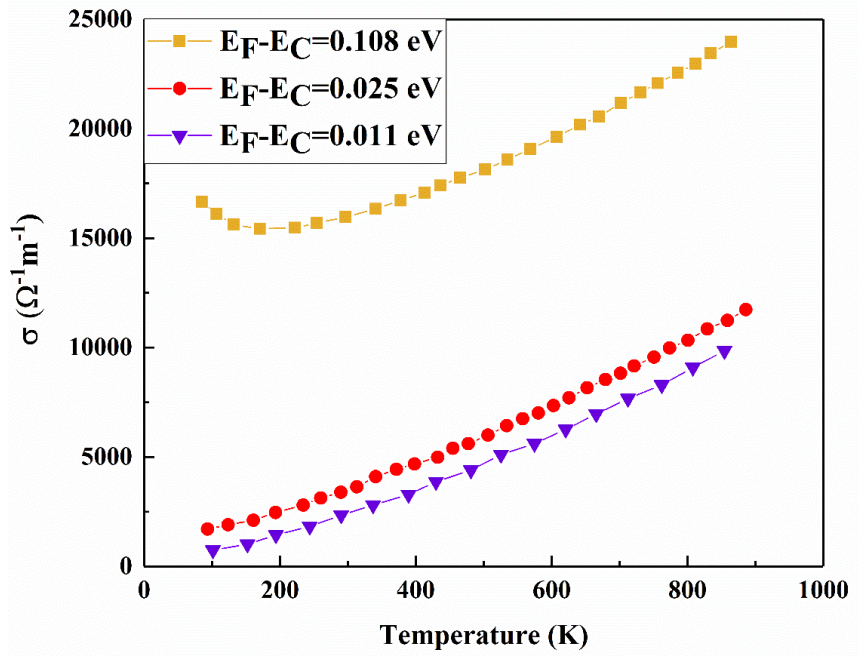

Fig. 5 Temperature dependence of electrical conductivity of $\operatorname{InN}^{63}$.

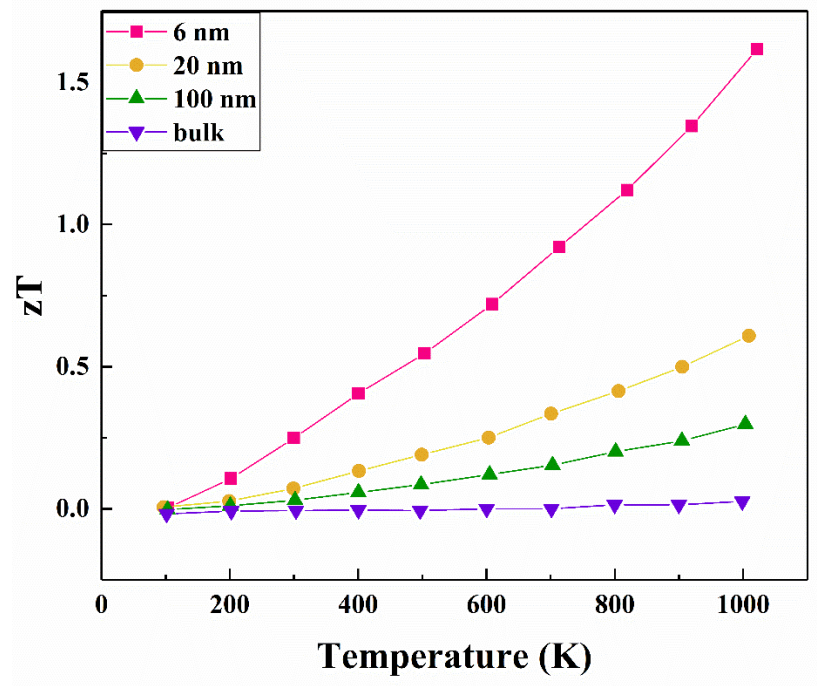

Fig. 6 Temperature dependence of TE properties of $\mathrm{InN}^{65}$.

\subsubsection{InGaN}

Indium gallium nitride $(\mathrm{InGaN})$ is a ternary alloy semiconductor that has the same wurtzite crystal structure as $\mathrm{GaN}$ and InN. InGaN combines the properties of $\mathrm{InN}$ and $\mathrm{GaN}$, arising from the ability to substitute In atoms in place of $\mathrm{Ga}$ atoms, or vice versa. InN has a band gap of $0.7 \mathrm{eV}$, but upon replacing a fraction (x) of $\mathrm{Ga}$ atoms with indium atoms, $\operatorname{In}_{1-x} \mathrm{Ga}_{x} \mathrm{~N}$ has a band gap that varies between 3.4 $\mathrm{eV}$ and $0.7 \mathrm{eV}$. This change in band gap will directly affect the Seebeck coefficient and therefore the overall TE performance of the materials. The effect on electrical conductivity is not obvious, however the thermal conductivity will decrease due to the addition of an element with a different mass.

Fig. 7 shows the TE transport properties versus temperature, assuming a carrier concentration of $1.1 \times 10^{19} \mathrm{~cm}^{-3}$ and a $0.17 \mathrm{InN}$ fraction. ${ }^{67}$ The power factor increases with the temperature increases due to the enhanced Seebeck coefficient. However, both electrical and thermal conductivity drop as temperature is increased. The trend for Seebeck coefficient versus temperature is common for most materials. Also, the reductions in both electrical and thermal conductivity due to the increase of phonon scattering as the temperature is raised. At a temperature of $875 \mathrm{~K}, z T$ attains a maximum of 0.34 , showing InGaN's applicability for high temperature TE applications.

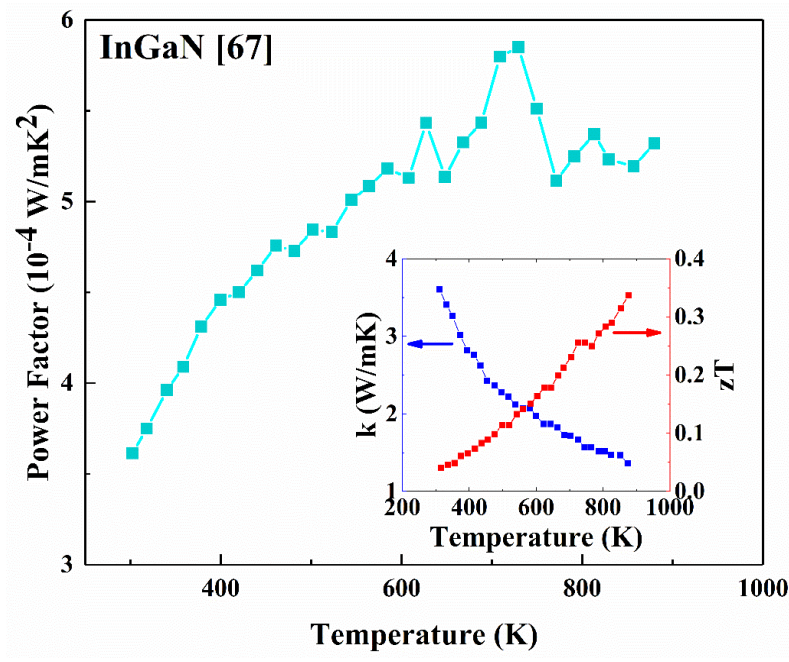

Fig. 7 Temperature dependence of TE properties of InGaN.

\subsubsection{AlGaN}

The high temperature TE properties of $\mathrm{AlGaN}$ have been described in several studies to date. Sztein et al. ${ }^{68}$ reported a simulation work on InGaN TE properties by using Callaway's approximation in tandem with a virtual crystal extension developed by B. Abeles, ${ }^{69}$ as shown in Fig. 8. As the temperature increases, as one would normally expect, the thermal conductivity, $\kappa$, decreases. However, Liu used Callaway's approximation ${ }^{70}$ for calculating the thermal conductivity, and it shows different results than expected. More investigations are needed to further explore the fundamental mechanisms.

With a higher concentration of $\mathrm{Al}$, we observe lower thermal conductivities generally due to the mass discrepancy in the three constituent elements ( $\mathrm{Al}, \mathrm{Ga}$, and $\mathrm{N}$ ), as shown in Fig. 8. The insert figure shows the $z T$ versus temperature. Tong et al. ${ }^{71}$ used $\mathrm{x}=0.4$ at all the temperatures while Sztein 68 used $\mathrm{x}=0.15$. zT increases with the increasing temperature, as does the optimum carrier density, ranging from $3 \times 10^{19} \mathrm{~cm}^{-3}$ at $300 \mathrm{~K}$ to $3 \times 10^{20} \mathrm{~cm}^{-3}$ at $1000 \mathrm{~K}$. The effect of different mass fractions, $\mathrm{x}$, on the figure of merit versus temperature is also shown in Figure 8. There is an increase in $z T$ as 
the concentration of aluminum (x) is decreased. However, the TE properties of $\mathrm{AlGaN}$ are not as promising as that of $\mathrm{InGaN}$ due to aluminum atoms being smaller than indium atoms, thus providing a smaller reduction in thermal conductivity.

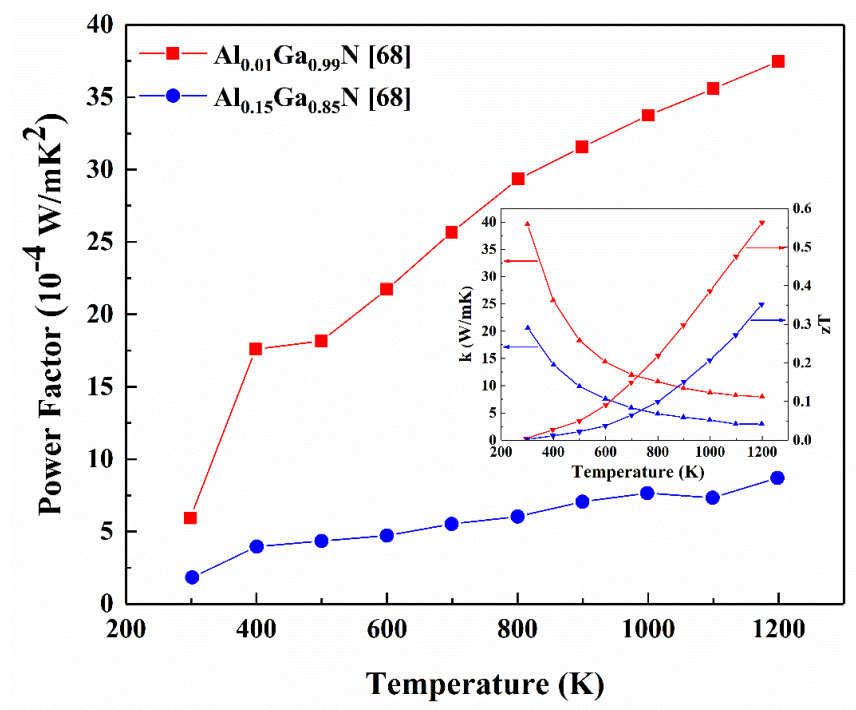

Fig. 8 Simulated temperature dependence of TE properties of AlGaN.

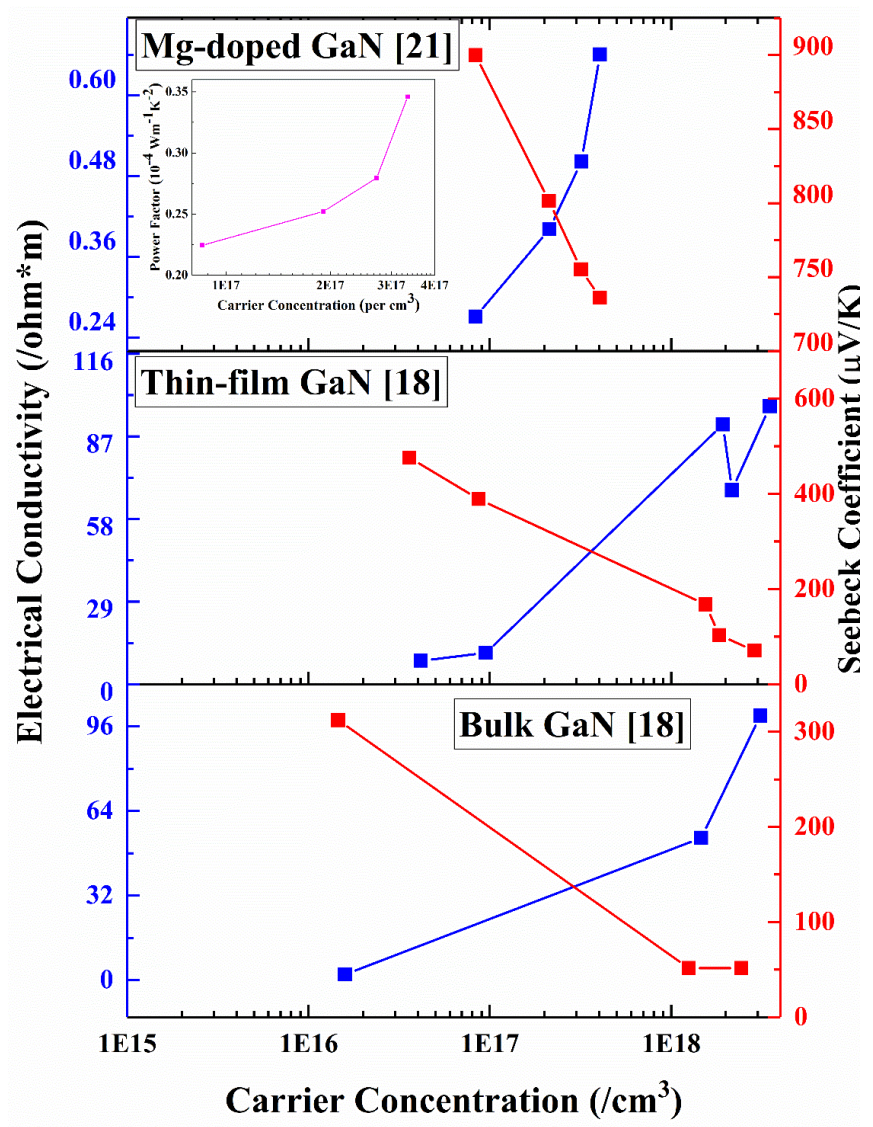

Fig. 9 TE properties vs carrier concentration of GaN.

\subsection{P-type Nitrides}

\subsubsection{GaN}

Gallium nitride $(\mathrm{GaN})$ typically has a wurtzite crystal or, under some growth conditions, a zinc blende crystal structure. ${ }^{72,73}$ The lattice constants of $\mathrm{GaN}$ are $3.186 \AA$ and $5.186 \AA$ for a and c, respectively. ${ }^{61}$ $\mathrm{GaN}$ has a large band gap of $3.4 \mathrm{eV}$, which is ideal for $\mathrm{TE}$ applications at higher temperature ranges. ${ }^{74}$ In Fig. 9 , all the materials attain their highest absolute value of the Seebeck coefficient at lower carrier concentrations, with a decreasing trend. They all display p-type behavior, which can be seen from the values of the Seebeck coefficient in Fig. 9. Lu et al. ${ }^{21}$ reported the highest Seebeck value for thin film Mg-doped $\mathrm{GaN}$ to be around $850 \mu \mathrm{V} / \mathrm{K}$, while for bulk $\mathrm{GaN}$ the highest values is around $300 \mu \mathrm{V} / \mathrm{K}$.

The highest $z T$ that was reported for a GaN structure was 0.8598 at a carrier concentration of $7 \times 10^{17} \mathrm{~cm}^{-3}$ at $300 \mathrm{~K}$ in the rough InN/GaN core shell nanowires. ${ }^{18}$ The lattice thermal conductivity dominates the thermal conductivity of materials at this low carrier concentration. Even though gallium has five times the atomic mass of nitrogen, bulk GaN has a relatively high lattice thermal conductivity at room temperature of several hundred $\mathrm{W} / \mathrm{mK}$, which is due to the fact that it only has two constituent elements. ${ }^{75}$ However, at higher temperature, increased phonon scattering causes a drastic reduction in lattice thermal conductivity. Wu et al. discussed that when the doping concentration reaches $1 \times 10^{19} \mathrm{~cm}^{-3}$, theoretically $z T$ could reach 1.713 at $1000 \mathrm{~K}, 18$ indicating that there is a possibility for this structure to be a good TE material at high temperature.

\subsubsection{CrN}

Chromium nitride $(\mathrm{CrN})$ exhibits a high power factor and an intrinsically lower thermal conductivity due to the rock-salt crystal structure, which provides a resonant boding effect. This results in a low thermal conductivity. There are limited studies on p-type doping $\mathrm{CrN}$, however, one promising p-type $\mathrm{CrN}$ material was reported using $\mathrm{Al}$ as a dopant. ${ }^{76}$

Fig. 10 shows the temperature dependent electrical properties of $\mathrm{Cr}_{0.96} \mathrm{Al}_{0.04} \mathrm{~N}_{1.17}$ thin film. The $\mathrm{Cr}_{0.96} \mathrm{Al}_{0.04} \mathrm{~N}_{1.17}$ film exhibited positive Seebeck coefficient value around $140 \mu \mathrm{V} / \mathrm{K}$ in the $400-600 \mathrm{~K}$. However, at room temperature and $773 \mathrm{~K}$, the Seebeck coefficient values were low $(\sim 100 \mu \mathrm{V} / \mathrm{K})$. The electrical resistivity decreases from around $30 \mathrm{~m} \Omega \cdot \mathrm{cm}$ at room temperature to less than $5 \mathrm{~m} \Omega \cdot \mathrm{cm}$ at $773 \mathrm{~K}$ as shown in Figure 10. The PF value is $0.37 \mathrm{~mW} / \mathrm{mK}^{2}$ at $773 \mathrm{~K}$.

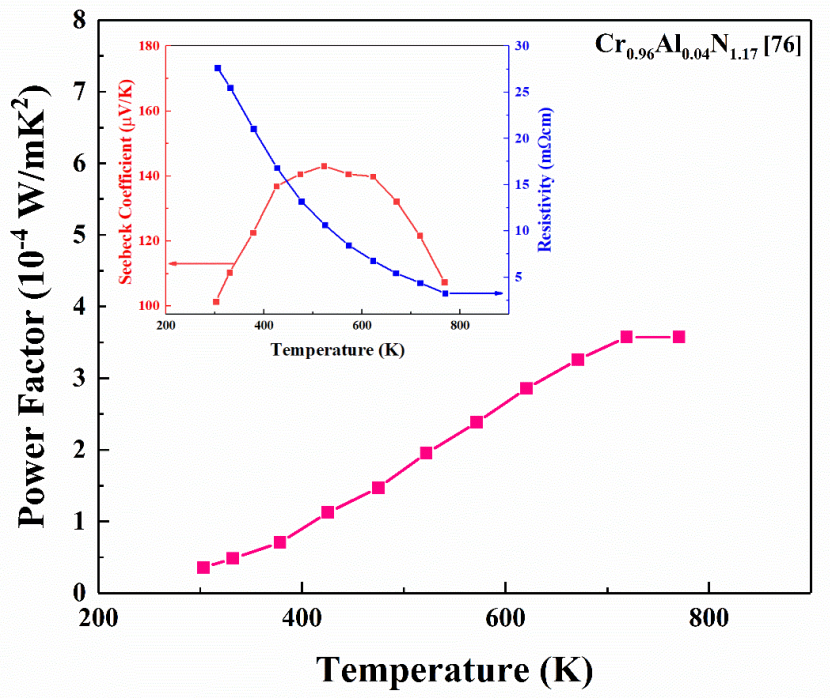

Fig. 10 TE properties vs carrier concentration of $\mathrm{CrN}$. 


\section{Summary}

Recently many advances have been made in metal oxides and nitrides based TE materials for power generation through waste heat harvesting. Both oxides and nitrides offer highly promising solutions for the development of non-toxic and cost effective TE power generation devices. The best $n$-type oxide material is $\mathrm{Sr}_{0.96} \mathrm{La}_{0.05} \mathrm{TiO}_{3}$ that reach power factor of $28 \times 10^{-4} \mathrm{~W} / \mathrm{mK}^{2}$ at $320 \mathrm{~K}$. However, $(\mathrm{ZnO}) \mathrm{Al}_{0.03} \mathrm{In}_{0.02}$ shows more promising applications for high temperature applications due to its thermal stability up to $1200 \mathrm{~K}$. Current highest power factor for p-type oxide material can reach at $18.92 \times 10^{-4} \mathrm{~W} / \mathrm{mK}^{2}$ at $\sim 1100 \mathrm{~K}$ with $\mathrm{Ag}$-doped $\mathrm{Na}_{\mathrm{x}} \mathrm{CoO}_{2}$. On the other hand, finding nitrides materials with good TE properties still remains challenging as discussed before.

Although oxides and nitrides have both shown promises and improvement as TE materials, there are still many challenges that must be overcome before they can be used commonly for power generation. The figure of merit is still lower than that of several other state of the art materials, such as $\mathrm{Bi}_{2} \mathrm{Ti}_{3}, \mathrm{SiGe}$. Additionally, finding better doping methods for high performance p-type materials will be necessary for the construction of bipolar devices such as TE generators. Despite these challenges, the many benefits of oxides and nitrides, such as their relative abundancy, low cost, stability, and ability to be electrically and thermally manipulated, in conjunction with their existing device fabrication infrastructure, ensure their future in the field of TE devices. Continuing to improve their performance and finding more materials with good properties is necessary for the next generation of TE generators, solar cells, gas sensors, and photodetectors.

\section{Conflict of interest}

There are no conflicts to declare.

\section{Acknowledgements}

The authors at Purdue University are grateful for the financial supports from National Science Foundation CAREER program (under Grants of CMMI - 1560834) and Purdue University Summer Undergraduate Research Fellowship.

\section{References}

1. G. J. Snyder and E. S. Toberer, Nat. Mater, 2008, 7, 105-114.

2. E. N. Hurwitz, M. Asghar, A. Melton, B. Kucukgok, L. Su, M. Orocz, M. Jamil, N. Lu and I. T. Ferguson, J. Electron. Mater, 2011, 40, 513-517.

3. C. Zhou, A. Ghods, V. G. Saravade, P. V Patel, K. L. Yunghans, C. Ferguson, Y. Feng, B. Kucukgok, N. Lu and I. T. Ferguson, ECS J. Solid State Sci. Technol., 2017, 6, 149-156.

4. N. Lu, C. Zhou, Y. Wang, A. M. Elquist, A. Ghods, I. T. Ferguson and V. G. Saravade, in Oxide-based Materials and Devices IX, eds. F. H. Teherani, D. C. Look and D. J. Rogers, SPIE, 2018, 10533, 53.

5. Y. Feng, X. Jiang, E. Ghafari, B. Kucukgok, C. Zhang, I. Ferguson and N. Lu, Adv. Compos. Hybrid Mater., 2018, 1, 114-126.

6. T. M. Tritt, Annu. Rev. Mater. Res., 2011, 41, 433-448.

7. A. Shakouri, Annu. Rev. Mater. Res., 2011, 41, 399-431.

8. C. S. Kim, G. S. Lee, H. Choi, Y. J. Kim, H. M. Yang, S. H. Lim, S. G. Lee and B. J. Cho, Appl. Energy, 2018, 214, 131-138.

9. N. Lu and S. Oza, Compos. Part B Eng., 2013, 44, 484-490.

10.M. S. Dresselhaus, G. Chen, M. Y. Tang, R. G. Yang, H. Lee, D.
Z. Wang, Z. F. Ren, J.-P. Fleurial and P. Gogna, Adv. Mater., 2007, 19, 1043-1053.

11.Q. Hao, D. Xu, N. Lu and H. Zhao, Phys. Rev. B, 2016, 93, 205206.

12.Q. Hao, H. Zhao and N. Lu, MRS Proc., 2015, 1774, 25-30.

13.A. Shakouri, Annu. Rev. Mater. Res., 2011, 41, 399-431.

14.B. Kucukgok, B. Hussain, C. Zhou, I. T. Ferguson and N. Lu, MRS Proc., 2015, 1805, mrss15-2136936.

15.M. Lee, L. Viciu, L. Li, Y. Wang, M. L. Foo, S. Watauchi, R. A. Pascal Jr, R. J. Cava and N. P. Ong, Nat. Mater., 2006, 5, 537-540.

16.H. Ohta, K. Sugiura and K. Koumoto, Inorg. Chem., 2008, 47, 8429-8436.

17.K. Koumoto, Y. Wang, R. Zhang, A. Kosuga and R. Funahashi, Annu. Rev. Mater. Res., 2010, 40, 363-394.

18.C.-W. Wu and Y.-R. Wu, J. Appl. Phys., 2014, 116, 103707.

19.B. Kucukgok, X. Wu, X. Wang, Z. Liu, I. T. Ferguson and N. Lu, AIP Adv., 2016, 6, 025305.

20.Z. Liu, J. Ma, X. Yi, E. Guo, L. Wang, J. Wang, N. Lu, J. Li, I. Ferguson and A. Melton, Appl. Phys. Lett., 2012, 101, 261106.

21.B. Kucukgok, B. Hussain, C. Zhou, I. T. Ferguson and N. Lu, MRS Proc., 2015, 1774, 13-18.

22.N. Lu and I. Ferguson, Semicond. Sci. Technol., 2013, 28, 074023.

23.Z. Guo, Y. Chen and N. L. Lu, Multifunctional nanocomposites for energy and environmental applications, John Wiley \& Sons, 2018.

24.B. Hussain, M. Y. Akhtar Raja, N. Lu and I. Ferguson, in 2013 High Capacity Optical Networks and Emerging/Enabling Technologies, IEEE, 2013, 88-93.

25.E. Ghafari, Y. Feng, Y. Liu, I. Ferguson and N. Lu, Compos. Part B Eng., 2017, 116, 40-45.

26.P. Jood, R. J. Mehta, Y. Zhang, G. Peleckis, X. Wang, R. W. Siegel, T. Borca-Tasciuc, S. X. Dou and G. Ramanath, Nano Lett., 2011, 11, 4337-4342.

27.B. Hussain, B. Kucukgok, M. Y. A. Raja, B. Klein, N. Lu and I. T. Ferguson, in Oxide-based Materials and Devices $V$, eds. F. H. Teherani, D. C. Look and D. J. Rogers, 2014, 898718.

28.K. B., W. B., M. A. G., L. N. and F. I. T., Phys. Status Solidi c, 11, 894-897.

29.K. Jung, K. H. Lee, W. Seo and S. Choi, 2012, 253902, 1-5.

30.S. Teehan, H. Efstathiadis and P. Haldar, J. Alloys Compd., 2011, 509, 1094-1098.

31.N. Lu, C. Zhou, Y. Wang, A. M. Elquist, A. Ghods, I. T. Ferguson and V. G. Saravade, in Oxide-based Materials and Devices IX, eds. F. H. Teherani, D. C. Look and D. J. Rogers, SPIE, 2018, vol. 10533, p. 53.

32.K. Koumoto, R. Funahashi, E. Guilmeau, Y. Miyazaki, A. Weidenkaff, Y. Wang and C. Wan, J. Am. Ceram. Soc., 2013, 96, $1-23$.

33.A. Nag and V. Shubha, J. Electron. Mater., 2014, 43, 962-977.

34.M. Ahrens, R. Merkle, B. Rahmati and J. Maier, Phys. B Condens. Matter, 2007, 393, 239-248.

35.A. Mehdizadeh Dehkordi, S. Bhattacharya, T. Darroudi, J. W. Graff, U. Schwingenschlögl, H. N. Alshareef and T. M. Tritt, Chem. Mater., 2014, 26, 2478-2485.

36.S. Ohta, T. Nomura, H. Ohta and K. Koumoto, J. Appl. Phys., 2005, 97, 034106.

37.T. Okuda, K. Nakanishi, S. Miyasaka and Y. Tokura, Phys. Rev. B, 2001, 63, 113104. 
38.S. Walia, S. Balendhran, H. Nili, S. Zhuiykov, G. Rosengarten, Q. H. Wang, M. Bhaskaran, S. Sriram, M. S. Strano and K. Kalantarzadeh, Prog. Mater. Sci., 2013, 58, 1443-1489.

39.H. Ohta, Mater. Today, 2007, 10, 44-49.

40.L. Zhang, T. Tosho, N. Okinaka, T. Akiyama, Mater. Trans., 2007, 8, 2088-2093.

41.H. C. Wang, C. L. Wang, W. Bin Su, J. Liu, Y. Sun, H. Peng and L. M. Mei, J. Am. Ceram. Soc., 2011, 94, 838-842.

42.I. Terasaki, Y. Sasago and K. Uchinokura, Phys. Rev. B, 1997, 56, R12685-R12687.

43.Q. Li, Z. Lin and J. Zhou, J. Electron. Mater., 2009, 38, 1268-1272.

44.X. C. Tong, Advanced materials for thermal management of electronic packaging, Springer, 2011.

45.N. Li, Y. Jiang, G. Li, C. Wang, J. Shi and D. Yu, J. Alloys Compd., 2009, 467, 444-449.

46.M. Ito and D. Furumoto, J. Alloys Compd., 2008, 450, 517-520.

47.A. Bhaskar, C.-J. Liu, J. J. Yuan and C.-L. Chang, J. Alloys Compd., 2013, 552, 236-239.

48.G. Xu, R. Funahashi, M. Shikano, I. Matsubara and Y. Zhou, Appl. Phys. Lett., 2002, 80, 3760-3762.

49.R. Tian, R. Donelson, C. D. Ling, P. E. R. Blanchard, T. Zhang, D. Chu, T. T. Tan and S. Li, J. Phys. Chem. C, 2013, 117, 13382-13387.

50.A. Bhaskar, Z.-R. Yang and C.-J. Liu, Ceram. Int., 2015, 41, 10456-10460.

51.Y. Wang, Y. Sui, J. Cheng, X. Wang and W. Su, J. Phys. Condens. Matter, 2007, 19, 356216.

52.J. W. Fergus, J. Eur. Ceram. Soc., 2012, 32, 525-540.

53.N. Van, N. ; Liu and C.-J. ; Ohtaki, J. Alloys Compd., 2018, 491, 53-56.

54.Y. Wang, Y. Sui, X. Wang, W. Su and X. Liu, J. Appl. Phys., 2010, 107, 033708.

55.Z. Liu, X. Yi, Z. Yu, G. Yuan, Y. Liu, J. Wang, J. Li, N. Lu, I. Ferguson and Y. Zhang, Sci. Rep., 2016, 6, 19537.

56.B. N. Pantha, R. Dahal, J. Li, J. Y. Lin, H. X. Jiang and G. Pomrenke, Appl. Phys. Lett., 2008, 92, 42112.

57.A. Sztein, H. Ohta, J. Sonoda, A. Ramu, J. E. Bowers, S. P.
DenBaars and S. Nakamura, Appl. Phys. Express, 2009, 2, 11103.

58.A. Sztein, J. E. Bowers, S. P. Denbaars and S. Nakamura, Appl. Phys. Lett., 2014, 104, 042106.

59.E. N. Hurwitz, M. Asghar, A. Melton, B. Kucukgok, L. Su, M. Orocz, M. Jamil, N. Lu and I. T. Ferguson, J. Electron. Mater., 2011, 40, 513-517.

60.L. P. Hu, T. J. Zhu, Y. G. Wang, H. H. Xie, Z. J. Xu and X. B. Zhao, Npg Asia Mater., 2014, 6, e88.

61.M. Levinshtein, S. Rumyantsev, M. Shur, V. Bougrov and A. Zubrilov, Properties of Advanced Semiconductor Materials: GaN, AIN, InN, BN, SiC, SiGe, Wiley-Interscience, 2001.

62.F. Morales, J. Mánuel, R. García, B. Reuters, H. Kalisch and A. Vescan, J. Phys. D. Appl. Phys., 2013, 46, 245502.

63.Z. M. Gibbs, H.S. Kim, H. Wang, G. J. Snyder, Z. M. Gibbs, H.S. Kim, H. Wang and G. J. Snyder, 2015, 022112, 0-5.

64.S. P. Fu and Y. F. Chen, Appl. Phys. Lett., 2004, 85, 1523-1525.

65.J. Ma, W. Li and X. Luo, Appl. Phys. Lett., 2014, 105, 82103.

66.L. D. Hicks and M. S. Dresselhaus, Phys. Rev. B, 1993, 47, 16631-16634.

67.A. Sztein, H. Ohta, J. E. Bowers, S. P. Denbaars and S. Nakamura, J. Appl. Phys., 2011, 110, 123709.

68.A. Sztein, J. Haberstroh, J. E. Bowers, S. P. Denbaars and S. Nakamura, J. Appl. Phys., 2013, 113, 183707.

69.B. Abeles, Phys. Rev., 1963, 131, 1906-1911.

70.J. Callaway, Phys. Rev., 1959, 113, 1046-1051.

71.H. Tong, H. Zhao, V. A. Handara, J. A. Herbsommer and N. Tansu, SPIE, 2009, 7211, 721103-721111.

72.B. M. Shi, M. H. Xie, H. S. Wu, N. Wang and S. Y. Tong, Appl. Phys. Lett., 2006, 89, 2004-2007.

73.E. N. Hurwitz, M. Asghar, A. Melton, B. Kucukgok, L. Su, M. Orocz, M. Jamil, N. Lu and I. T. Ferguson, J. Electron. Mater. 2011, 40, 513-517.

74.B. G. Streetman and S. Banerjee, Solid state electronic devices, Upper Saddle River, N.J. : Prentice Hall, 5th ed., 2000.

75.M. D. Kamatagi, N. S. Sankeshwar and B. G. Mulimani, Diam. Relat. Mater., 2007, 16, 98-106.

76.A. Le Febvrier, N. Van Nong, G. Abadias and P. Eklund, Appl. Phys. Express, 2018, 11, 051003. 